\title{
Demographic Pattern of Self-Injurious Behaviours among Secondary School Students in Imo State
}

\author{
Benedicta Ndidi Agu ${ }^{1}$, Chuks Emmanuel Ezedum ${ }^{1,2}$, Olaoluwa Samson Agbaje ${ }^{1, *}$ \\ ${ }^{1}$ Department of Public Health, Faculty of Health Sciences, Madonna University Elele, Rivers State, Nigeria \\ ${ }^{2}$ Department of Health and Physical Education, Faculty of Education, University of Nigeria, Nsukka, Nigeria
}

\section{Email address:}

benemdi@yahoo.com (B. N. Agu), chukseezedum@yahoo.com (C. E. Ezedum), agbajesam@yahoo.com (O. S. Agbaje)

\section{To cite this article:}

Benedicta Ndidi Agu, Chuks Emmanuel Ezedum, Olaoluwa Samson Agbaje. Demographic Pattern of Self-Injurious Behaviours Among Secondary School Students in Imo State. Science Journal of Public Health. Vol. 3, No. 3, 2015, pp. 321-330.

doi: $10.11648 /$ j.sjph.20150303.14

\begin{abstract}
Self-injurious behaviours patterns among secondary school students in Imo State were investigated as a basis for proffering preventive strategies. The study utilized cross-sectional survey design. The population of the study consisted of 173,285 secondary school students in Imo State secondary schools. A sample of 2,160 students representing 1.2 per cent of the population participated in the study. Multi-stage sampling procedure was adopted to draw the sample from the population. A nine-item structured questionnaire was used for quantitative data collection while Focus Group Discussion Guide-FGDG was used for collecting qualitative data which were used to complement quantitative data. Cronbach's Alpha statistic was employed to establish the reliability co-efficient of the instrument. The reliability coefficient value of 0.78 was obtained. Mean statistic and standard deviation were used to analyze research questions while student t-test statistic and Analysis of Variance (ANOVA) were used to test the five null hypotheses at .05 level of significance. Findings of the study indicated that there were significant $(\mathrm{p}<0.05)$ differences in the self-injurious behaviours of secondary school students according to age $(\mathrm{F}=20.69>3.00)$, school type $(F=20.97)$ and education zone $(F=6.31>3.00)$. Recommendations such as Imo State Ministries of Health and Information should lend logistic and manpower support to the State Universal Basic Education Board in the implementation of intervention strategies in schools and there should be state-wide public health campaign in secondary schools against selfinjurious behaviours.
\end{abstract}

Keywords: Self-Injuries, Health, Behaviours, Suicide, Prevention Strategies

\section{Introduction}

It is often believed that a healthy lifestyle is a valuable resource for reducing the incidence and impact of health risks, enhancing recovery, coping with life stressors and improving quality of life. However, almost everybody exhibits unhealthy lifestyles in one form or the other (1). This includes secondary school students $(2,3)$. It appears, however, that secondary school students indulge in unhealthy lifestyles more than their out-of-school counterparts. In-school male students are more likely than out-of-school male students to indulge in unhealthy lifestyles (1). This may however be attributed to their conditions of life, which involve tension and environmental factors that expose them to exhibition of unhealthy lifestyles more than out-of-school students (2-3, 4, $5)$. In addition, a sizable proportion of the ten leading causes of death among youths were due to potentially modifiable social and lifestyle factors (6).

Literature shows that there is no clear consensus in literature about the definition or the key elements that constitute the concept of unhealthy lifestyles (7). While it is generally agreed that such lifestyles are associated with increased risks of mortality, morbidity, and disability, there is uncertainty about whether specific lifestyles are associated with acute adverse outcomes (1). Unhealthy lifestyles have been categorized into substance abuse, inadequate exercise, and poor dietary practices as they relate to being over-weight and intentional injuries. Another typology of unhealthy lifestyles include self-injurious behaviours (non-suicidal selfinjury, suicidal behaviours and suicide); substance use (alcohol abuse, tobacco and drug abuse); risky sexual behaviours (sex-work); behaviours related to obesity and unhealthy dieting (unhealthy diet) and inactivity or lack of exercise $(8,27)$. This study restricted its scope to selfinjurious behaviours (SIBs). 
Defining self-injurious behaviors (SIBs) presents some difficulties. SIB has been broadly defined as behavior that produces injury to the individual's own body, (9) and thus could be seen as including suicide, self-neglect, substance abuse, malingering, and so forth-all terms that infer some intent on the part of the client. Self-injurious behaviours (SIBs) are multiple and diverse in their presentation and often bewildering and vexing in the powers that drive them, their frequently blatant self-destructiveness and the call for effective intervention (10).

SIBs refer to all behaviours involving deliberate infliction of direct physical harm to one's own body without any intent to die as a consequent of the behavior. In this definition, the term deliberate implies conscious intents rather than unconsciously driven motivation; accident-prone individuals, for example may have an unconscious need to be injured or injure themselves but do not do it "deliberately" (10). On the other hand, an individual who self-injures during dissociative episode may have no memory of performing the behaviour but may have had conscious intent to self-injure while in an altered state. Direct physical harm implies that the injury is pretty most immediate in impact, liver damage caused by alcohol consumption or lung destruction caused by smoking would not be included here, even if known to the subject. The physical injury may be external such as skin cutting or picking or internal such as ingestion of sharp objects commonly found in prison populations. Without any intent to die implies just that, because the intensity and seriousness of suicidal intent can be variable and ambivalence is commonly encountered (10).

Moreover, SIBs are classified into four categories namely: stereotypic, major, compulsive and impulsive (11-12). Behaviours that fall into the stereotypic category include head banging, self-hitting, lip or hand chewing, skin picking or scratching, self-biting and hair pulling while behaviours that are classified under major category include: castration, eye enucleation, and limb amputation. Furthermore, behaviours that typify compulsive SIBs include: hair pulling, skin biting and nail puling while behaviours classified under impulsive category include: skin burning, skin cutting and self-hitting $(11,12)$. The study was focused on secondary school students because majority of them inclined to SIBs and other forms of injuries (13-15). The magnitude, characteristics and pattern of injury vary considerably from country to country (15). International Union for Health Promotion and Education (IUHPE) also condemned unhealthy lifestyles including SIBs in whichever pattern it is practiced.

Pattern has been defined as various forms in which something may occur (16). It also refers to the regular ways in which something happens or is done (17). In this study, pattern refers to the regular ways in which SIBs occur or happen among students. Patterns can be classified into three forms, namely: demographic, temporal and spatial (18). This study focused on demographic pattern. Demographic pattern has been conceptualized as the pattern which encompasses variable such as age, gender, level of education, marital status, occupation, socio-economics and health status as well as race/ethnicity (18). Demographic is a concept pertaining to characteristics of the population, such as race, sex, age, household size, population growth and density (19). Demographic pattern in this study refers to the manifestation of SIBs with respect to such demographic variables as age, gender, class of students, school type and education zone.

The desire to change secondary school students' behaviours in relation to self-injurious behaviours through healthy lifestyle activity programmes, justifies the use of behaviour change theories. Although, a number of theories have been developed to promote changes in behaviours for reducing future health risks, few tested models that focus on prevention of self-injurious behaviours were examined. Models help in interventions to promote change in lifestyles for reducing the risk of future illness and should be based upon theoretical models that identify the determinants of lifestyles change (20). Theoretical models relevant in the context of the study include: theory of causation and liability in law, biological based theories of risk taking and social bonding theory (21-23).The tenets of the aforementioned theories were reviewed and applied in relation to pattern of SIBs among secondary school students in Imo State.

The magnitude, characteristics and pattern of injury including SIBs vary considerably from country to country (15). Yet, school-based injury as a research problem has been largely ignored in developing countries including Nigeria. Few studies have described the pattern of injuries, and associated factors, in Nigeria. However, the majority of these studies have been hospital-based which providedinformation on severe injuries (13). It is apparent that many self-inflicted injuries among schooling adolescents do not result into hospitalization. Hospital-based studies conducted on SIBs among adolescents represent the iceberg phenomenon while majority of SIBs cases are not reported or underreported. Consequently, based on these limitations, it is evident that school-based study may be considered a simple and better approach to understand more accurately the pattern of SIBs among students. However, surveys conducted on SIBs among adolescent students in Nigeria are poorly understood, as a result there is dearth of accurate information on SIBs among schooling adolescents. Therefore, to design valid prevention strategies for schools in Nigeria including Imo State, this study examined the pattern of SIBs among schooling adolescents in reference to age, gender, class, school-type and education zone.

\section{Purpose of the Study}

The purpose of the study was to determine demographic pattern of self-injurious behaviours among students in Imo State secondary schools as a basis for proffering suitable preventive strategies. Specifically, the study sought to:

1. pattern of SIBs among secondary school students in Imo State;

2. pattern of SIBs among secondary school students in Imo State based on age;

3. pattern of SIBs among secondary school students in Imo 
State based on gender;

4. pattern of SIBs among secondary school students in Imo State based on class;

5. pattern of SIBs among secondary school students in Imo State based on school type, and

6. pattern of SIBs among secondary school students in Imo State based on education zone.

\subsection{Research Questions}

Based on specific objectives, the following research questions were formulated:

1. What is pattern of SIBs among secondary school students in Imo State?

2. What is pattern of SIBs among secondary school students in Imo State based on age?

3. What is the pattern of SIBs among secondary school students in Imo State based on gender?

4. What is the pattern of SIBs among secondary school students in Imo State based on class?

5. What is the pattern of SIBs among secondary school students in Imo State based on school type?

6. What is the pattern of SIBs among secondary school students based on education zone?

\subsection{Hypotheses}

In order to further give direction to this study, the following hypotheses were formulated

1. There is no significant difference in the demographic pattern of self-injurious behaviours of students according to age.

2. There is no significant difference in the demographic pattern of self-injurious behaviours of students according to gender.

3. There is no significant difference in pattern of selfinjurious behaviours of students based on school type.

4. There is no significant difference in the pattern of selfinjurious behaviours of students based on education zone.

5. There is no significant difference in demographic pattern of self-injurious behaviours based on class.

\section{Materials and Methods}

Cross-sectional survey design was utilized for the study. The population of the study comprised 173,285 (Secondary Education Management Board, 2009).The study covered both Government and Private Schools). These schools were located in the education zones of Imo State, namely: Okigwe, Orlu and Owerri. The sample for the study consisted of 2,160 students which represented 1.2 per cent of the population. Multistage sampling procedure was used for sample selection. The first stage involved use of non-proportionate stratified random sampling technique to select three public and three private secondary schools each from the three education zones (Okigwe, Orlu and Owerri). The secondary schools were stratified into three strata, namely: boys' exclusive, girls' exclusive and mixed/co-education schools. This produced a total of 18 secondary schools.

The second stage involved use of simple random sampling technique of balloting without replacement to select three streams (A, B, \& C) in each class of the sampled four classes (Junior Secondary Schools One and Two (JSS $1 \&$ JSS 2) and Senior Secondary Schools One and Two (SS $1 \&$ SS 2). The process produced a total of 12 streams per school and 216 streams in all the sampled 18 secondary schools. Convenience sampling technique was used to select ten students each from each of the three selected streams. This yielded 30 students per class and a total of 120 students per school with the cumulative total of 2,160 students in all the 18 selected secondary schools in the three education zones.

A nine-item structured questionnaire on Students' Pattern of SIBs was used for collection of quantitative data. The instrument has two sections, namely: Sections A and B. Section A contained five socio-demographic variables (age, gender, education zone, school type and class of students) while Section B contained four items for eliciting information on SIBs. This section consisted of four structured questions on a Likert-type scale of 'Always', 'Occasionally', and 'Never'. The subjects were requested to tick $(\sqrt{ })$ against their chosen response options. Validity of the instrument was established by five experts in the Department of Sociology and Anthropology, Department of Health and Physical Education, Department of Science Education and Psychology Department, University of Nigeria, Nsukka. Cronbach's alpha statistic was utilized to determine the correlation coefficient of the items in section B of the instrument. The reliability co-efficient of the instrument was 0.79 . Furthermore, a sample of 72 students that comprised 36 male and 36 female students was randomly selected from the initial sample of 2,160 students for the focus group discussions-FGDs. A total of 12 FGDs were formed. Each FGD comprised six students, which was made of three male and three female students. The FGD guide consisted of three open-ended questions, which were used to elicit information from students on SIBs. Written permission was obtained from Principal (administrative head) of each participating schools and from all classroom teachers. In addition, research participants were asked to give their informed consent through the signing of a consent form before any responses were solicited from them.

Quantitative data were analysed using the Statistical Package for Social Sciences-SPSS version 16 while qualitative data were analysed through content coding procedures based on a set of predetermined themes of interest. The questions were: 1) Do students of this school engage in physical fight/intentionally inflict injuries on others? 2) What are the ways that students engage in SIBs? 3) What are the common self-injurious behaviours among students?

The data were analyzed on an item-by- item basis. Data analysis was performed by using 2,119 properly filled copies of the structured questionnaire. Mean statistic was used to analyze data answering the research questions. The response options for section B were weighted as 'Always' (3 points), 
'Occasionally' ( 2 points), and 'Never' (1 point). The limits of numbers as well as grand mean scores were applied to interpret the data. Hence, mean scores ranging between 2.50 to 3.00 were interpreted as 'Always', while mean scores ranging between 1.50 and 2.49 were interpreted as 'Occasionally' and mean scores between 1.00 and 1.49 were interpreted as 'Never' which was an indication that such SIB was not in practice. Student t-test was used for parametric variables and where appropriate one-way ANOVA was also used to assess significant differences. All reported $\mathrm{P}$ values were made on the basis of two-tailed tests. Differences were considered statistically significant at $\mathrm{P}$ value $<0.05$.

\section{Results}

\section{Research Question 1}

What is the pattern of self-injurious behaviours (SIBs) among secondary school students in Imo State?

Table 1. Mean score Analysis of the SIBs among Secondary School Students in Imo State $(n=2,119)$.

\begin{tabular}{|c|c|c|c|c|}
\hline & Self-injurious behaviours & $\bar{X}$ & SD & Decision \\
\hline 1. & How often have you sustained minor injuries while bullying any of your school mates? & 2.07 & 0.729 & Always \\
\hline 2. & I have taken poison/any poisonous substance to kill myself in the past 12 months. & 1.06 & 0.280 & Never \\
\hline 3. & Have you ever jumped from a high building to kill yourself? & 1.07 & 0.296 & Never \\
\hline \multirow{2}{*}{4.} & How often have you been involved in inflicting injuries on self during physical fight anywhere? & 1.40 & 0.599 & Never \\
\hline & Grand Mean & 1.40 & 0.476 & Never \\
\hline
\end{tabular}

Table 1 shows that bullying of school mates with minor injuries $(\bar{X}=2.07$; $\mathrm{SD}=0.73)$ is the common form of SIB identified among secondary schools students in Imo State. The grand mean shows that students never engaged in SIBs $(\bar{X}=1.40 ; \mathrm{SD}=0.48)$.
Research Question 2

What is the pattern of SIBs among secondary school students based on age?

Table 2. Mean Score Analysis of SIBs among Secondary School Students according to Age $(n=2,119)$.

\begin{tabular}{|c|c|c|c|c|c|c|c|c|c|c|}
\hline \multirow{3}{*}{$\mathbf{S} / \mathbf{n}$} & \multirow{3}{*}{ Item } & \multicolumn{9}{|c|}{ AGE } \\
\hline & & \multicolumn{3}{|c|}{$10-13$ years $(n=575)$} & \multicolumn{3}{|c|}{$14-17$ years $(n=1252)$} & \multicolumn{3}{|c|}{ Above 17 years $(n=292)$} \\
\hline & & $\bar{X}$ & SD & Dec. & $\bar{X}$ & SD & Dec. & $\bar{X}$ & SD & *Dec. \\
\hline 1 & $\begin{array}{l}\text { How often have you sustained minor injuries while } \\
\text { bullying any of your school mates? }\end{array}$ & 1.50 & .63 & $\mathrm{O}$ & 1.64 & .62 & $\mathrm{O}$ & 1.51 & .61 & $\mathrm{O}$ \\
\hline 2 & $\begin{array}{l}\text { I have taken poison/any poisonous substance to kill } \\
\text { self in the past } 12 \text { months }\end{array}$ & 1.02 & .13 & $\mathrm{~N}$ & 1.10 & .33 & $\mathrm{~N}$ & 1.11 & .35 & $\mathrm{~N}$ \\
\hline 3 & $\begin{array}{l}\text { Have you ever jumped from a high building to kill } \\
\text { yourself? }\end{array}$ & 1.03 & .17 & $\mathrm{~N}$ & 1.14 & .41 & $\mathrm{~N}$ & 1.11 & .36 & $\mathrm{~N}$ \\
\hline \multirow[t]{2}{*}{4} & $\begin{array}{l}\text { How often have you been involved in inflicting } \\
\text { injuries on yourself during physical fight anywhere }\end{array}$ & 1.25 & .51 & $\mathrm{~N}$ & 1.34 & .55 & $\mathrm{~N}$ & 1.59 & .63 & $\mathrm{O}$ \\
\hline & Grand mean & 1.20 & .36 & $\mathrm{~N}$ & 1.31 & .48 & $\mathrm{~N}$ & 1.33 & .49 & $\mathrm{~N}$ \\
\hline
\end{tabular}

$*^{*} \mathrm{~N}=$ Never, ${ }^{*} \mathrm{O}=$ Occasionally

Table 2 indicates that respondents in all age categories occasionally sustained minor injuries while bullying their school mates $(10-13$ years $\bar{X}=1.50 ; \mathrm{SD}=.63 ; 14-17$ years $\bar{X}=1.64 ; \mathrm{SD}=.62$; above 17 years $\bar{X}=1.51 ; \mathrm{SD}=.61$ ). Grand mean scores indicate that secondary school students never exhibited SIBs according to age. This was evident from their mean scores as follows: 10-13 years (10-13 years $\bar{X}=1.20 ; \mathrm{SD}=.36 ; 14-17$ years $\bar{X}=1.31 ; \mathrm{SD}=.48$; above 17 years $\bar{X}=1.33$; $\mathrm{SD}=.49$ ).

Research Question 3

What is the pattern of SIBs among secondary school students based on gender?

Table 3. Mean Score Analysis of SIBs among Secondary School Students according to Gender $(n=2119)$.

\begin{tabular}{|c|c|c|c|c|c|c|c|}
\hline \multirow{3}{*}{$\mathbf{S} / \mathbf{N}$} & \multirow{3}{*}{ Items } & \multicolumn{6}{|c|}{ GENDER } \\
\hline & & \multicolumn{2}{|c|}{ Male $(n=1,061)$} & \multicolumn{4}{|c|}{ Female $(n=1,058)$} \\
\hline & & $\bar{X}$ & SD & Dec. & $\bar{X}$ & SD & Dec. \\
\hline 1 & $\begin{array}{l}\text { How often have you sustained minor injuries while bullying any of your school } \\
\text { mates? }\end{array}$ & 1.73 & .64 & $\mathrm{O}$ & 1.43 & .56 & $\mathrm{~N}$ \\
\hline 2 & I have taken poison/any poisonous substance to kill myself in the past 12 months & 1.05 & .25 & $\mathrm{~N}$ & 1.11 & .34 & $\mathrm{~N}$ \\
\hline 3 & $\begin{array}{l}\text { Have you ever jumped from a high building to kill } \\
\text { yourself? }\end{array}$ & 1.05 & .27 & $\mathrm{~N}$ & 1.16 & .43 & $\mathrm{~N}$ \\
\hline \multirow[t]{2}{*}{4} & $\begin{array}{l}\text { How often have you been involved in inflicting injuries on yourself during physical } \\
\text { fight anywhere }\end{array}$ & 1.38 & .57 & $\mathrm{~N}$ & 1.31 & .53 & $\mathrm{~N}$ \\
\hline & Grand mean & 1.30 & .43 & $\mathrm{~N}$ & 1.25 & .47 & $\mathrm{~N}$ \\
\hline
\end{tabular}

${ }^{*} \mathrm{~N}=$ Never, ${ }^{*} \mathrm{O}=$ Occasionally 
Data in Table 3 show that male respondents occasionally sustained minor injuries while bullying their school mates (Male $\bar{X}=1.73 ; \mathrm{SD}=.64$ ) while female students never (Female $\bar{X}=1.43$; SD $=.56$ ) sustained minor injuries while bullying their school mates. In addition, the grand mean scores on SIBs according to gender show that students never engaged in SIBs (Male $\bar{X}=1.30 ; \mathrm{SD}=.43$; Female $\bar{X}=1.25$; $\mathrm{SD}=.47)$.

Research Question 4

What is the pattern of SIBs among secondary school students based on school type?

Table 4. Mean Score Analysis of SIBs among Secondary School Students according to School Type $(n=2,119)$.

\begin{tabular}{|c|c|c|c|c|c|c|c|c|c|c|}
\hline & \multirow{3}{*}{ Items } & \multicolumn{9}{|c|}{ SCHOOL TYPE } \\
\hline & & \multicolumn{3}{|c|}{${ }^{*} \operatorname{EGSS}(\mathbf{n}=835)$} & \multicolumn{3}{|c|}{$* \operatorname{EBSS}(n=739)$} & \multicolumn{3}{|c|}{$* \operatorname{MXSS}(n=545)$} \\
\hline & & $\bar{X}$ & SD & Dec. & $\bar{X}$ & SD & Dec & $\bar{X}$ & SD & *Dec. \\
\hline 1. & $\begin{array}{l}\text { How often have you sustained minor injuries while bullying any } \\
\text { of your school mates? }\end{array}$ & 1.42 & .57 & $\mathrm{~N}$ & 1.75 & .64 & $\mathrm{O}$ & 1.60 & .63 & $\mathrm{O}$ \\
\hline 2. & I have taken poison to kill myself in the past 12 months & 1.10 & .30 & $\mathrm{~N}$ & 1.04 & .21 & $\mathrm{~N}$ & 1.11 & .39 & $\mathrm{~N}$ \\
\hline \multirow[t]{2}{*}{4.} & $\begin{array}{l}\text { How often have you been involved in inflicting injuries on } \\
\text { yourself during physical fight anywhere }\end{array}$ & 1.29 & .52 & $\mathrm{~N}$ & 1.40 & .57 & $\mathrm{~N}$ & 1.36 & .58 & $\mathrm{~N}$ \\
\hline & Grand mean & 1.25 & .46 & $\mathrm{~N}$ & 1.31 & .42 & $\mathrm{~N}$ & 1.29 & .48 & $\mathrm{~N}$ \\
\hline
\end{tabular}

$* \mathrm{~N}=\mathrm{Never}$

$* \mathrm{O}=$ Occasionally

*EGSS = Exclusively Girls' Secondary Schools

*EBSS = Exclusively Boys' Secondary Schools

*MXSS = Mixed Secondary Schools

Table 4 shows that respondents in EBSS and MXSS occasionally sustained minor injuries while bullying their school mates (EBSS $\bar{X}=1.75$; SD $=.64$; MXSS $\bar{X}=1.60$; SD $=.63)$. In contrast, student in EGSS never $(\bar{X}=1.42$; SD $=.57$ ) sustained minor injuries while bullying their mates.Grand mean scores indicate that secondary school students never exhibited SIBs irrespective of school type
$(\operatorname{EGSS} \bar{X}=1.25 ; \mathrm{SD}=.46 ;$ EBSS $\bar{X}=1.31 ; \mathrm{SD}=.42 ;$ above $\operatorname{MXSS} \bar{X}=1.29 ; \mathrm{SD}=.48$ ).

Research Question 5

What is the pattern of SIBs among secondary school students based on education zone?

Table 5. Mean Score Analysis of SIBs among Secondary School Students according to Education Zone $(n=2119)$.

\begin{tabular}{|c|c|c|c|c|c|c|c|c|c|c|}
\hline \multirow{3}{*}{$\mathbf{S} / \mathbf{N}$} & \multirow{3}{*}{ Items } & \multicolumn{9}{|c|}{ EDUCATION ZONE } \\
\hline & & \multicolumn{3}{|c|}{ *OKEZ $(n=659)$} & \multicolumn{3}{|c|}{ *OREZ $(\mathrm{n}=564)$} & \multicolumn{3}{|c|}{ *OWEZ $(\mathrm{n}=896)$} \\
\hline & & $\bar{X}$ & SD & Dec. & $\bar{X}$ & SD & Dec. & $\bar{X}$ & SD & *Dec \\
\hline 1. & $\begin{array}{l}\text { How often have you sustained minor injuries while bullying } \\
\text { any of your school mates? }\end{array}$ & 1.64 & .52 & $\mathrm{O}$ & 1.60 & .65 & $\mathrm{O}$ & 1.53 & .68 & *O \\
\hline 2. & I have taken poison to kill myself in the past 12 months & 1.08 & .34 & $\mathrm{~N}$ & 1.03 & .16 & $\mathrm{~N}$ & 1.12 & .34 & $\mathrm{~N}$ \\
\hline 3. & Have you ever jumped from a high building to kill yourself? & 1.04 & .23 & $\mathrm{~N}$ & 1.07 & .31 & $\mathrm{~N}$ & 1.18 & .45 & $\mathrm{~N}$ \\
\hline \multirow[t]{2}{*}{4.} & $\begin{array}{l}\text { How often have you been involved in inflicting injuries on } \\
\text { yourself during physical fight anywhere }\end{array}$ & 1.25 & .48 & $\mathrm{~N}$ & 1.42 & .55 & $\mathrm{~N}$ & 1.38 & .61 & $\mathrm{~N}$ \\
\hline & Grand mean & 1.25 & .39 & $\mathrm{~N}$ & 1.28 & .41 & $\mathrm{~N}$ & 1.30 & .52 & $\mathrm{~N}$ \\
\hline
\end{tabular}

Key

*OKEZ $=$ Okigwe Education Zone

$*$ OREZ $=$ Orlu Education Zone

*OWEZ $=$ Owerri Education Zone

Table 5 explicitly shows that respondents in all the education zones indicated occasionally sustained minor injuries during bullying (OKEZ $\bar{X}=1.64 ; \mathrm{SD}=.52$; OREZ $\bar{X}=1.60 ; \mathrm{SD}=.65$; OWEZ $\bar{X}=1.53$; SD $=.68)$. Grand mean scores indicate that secondary school students never exhibited SIBs irrespective of education zones
$($ OKEZ $\bar{X}=1.25 ; \mathrm{SD}=.39$; OREZ $\bar{X}=1.28 ; \mathrm{SD}=.41$; above OWEZ $\bar{X}=1.30 ; \mathrm{SD}=.52$ ).

Research Question 6

What is the pattern of SIBs among students according to class? 
Table 6. Mean Score Analysis of SIBs among Secondary School Students according to Class $(n=2,119)$.

\begin{tabular}{|c|c|c|c|c|c|c|c|}
\hline \multirow{3}{*}{$\mathbf{S} / \mathbf{N}$} & \multirow{3}{*}{ Items } & \multicolumn{6}{|c|}{ CLASS } \\
\hline & & \multicolumn{2}{|c|}{$* J S S(n=1036)$} & \multicolumn{4}{|c|}{$* \operatorname{SSS}(n=1083)$} \\
\hline & & $\bar{X}$ & SD & *Dec. & $\bar{X}$ & SD & *Dec. \\
\hline 6. & $\begin{array}{l}\text { How often have you sustained minor injuries while bullying any of } \\
\text { your school mates? }\end{array}$ & 1.62 & .67 & $\mathrm{O}$ & 1.54 & .58 & $* \mathrm{O}$ \\
\hline 10. & I have taken poison to kill myself in the past 12 months & 1.04 & .24 & $\mathrm{~N}$ & 1.12 & .35 & $\mathrm{~N}$ \\
\hline 13. & Have you ever jumped from a high building to kill yourself? & 1.04 & .22 & $\mathrm{~N}$ & 1.17 & .45 & $\mathrm{~N}$ \\
\hline \multirow[t]{2}{*}{21.} & $\begin{array}{l}\text { How often have you been involved in inflicting injuries on } \\
\text { yourselfduring physical fight anywhere }\end{array}$ & 1.31 & .53 & $\mathrm{~N}$ & 1.38 & .59 & $\mathrm{~N}$ \\
\hline & Grand mean & 1.25 & .41 & $\mathrm{~N}$ & 1.30 & .49 & $\mathrm{~N}$ \\
\hline
\end{tabular}

Key

*JSS = Junior Secondary School

*SSS = Senior Secondary School

Data in Table 3 show that JSS and SSS respondents occasionally sustained minor injuries while bullying their school mates (JSS $\bar{X}=1.62 ; \mathrm{SD}=.67$; SSS $\bar{X}=1.54$; SD $=.58$ ). In addition, the grand mean scores on SIBs according to class of students show that students never engaged in SIBs (JSS $\bar{X}=1.25 ; \mathrm{SD}=.41 ; \mathrm{SSS} \bar{X}=1.30 ; \mathrm{SD}=.49$ ).
Hypothesis 1

There is no significant difference $(\mathrm{p}<.05)$ in the mean demographic pattern of SIBs of secondary school students according to age. Data testing this hypothesis are contained in Table 7.

Table 7. One-way Analysis of Variance (ANOVA) of no Significant Difference in the Demographic Pattern of SIBs of Secondary School Students in Imo State according to Age $(n=2,119)$.

\begin{tabular}{|c|c|c|c|c|c|c|c|}
\hline Variable & $\mathbf{N}$ & Sources of VarianceF & Sum of Squares & df & Mean Squares & Cal. F & Table \\
\hline \multicolumn{8}{|l|}{ *Age } \\
\hline *SIB & 579 & BG & 74.250 & 2 & 37.125 & \multirow{3}{*}{20.694} & \multirow{3}{*}{3.00} \\
\hline $\begin{array}{l}10-13 \text { years } \\
14-17 \text { years }\end{array}$ & 1252 & WG & 3796.108 & 2116 & 1.794 & & \\
\hline 17 years + & 292 & & & & & & \\
\hline
\end{tabular}

* Significant at $\mathrm{p}<.05$

$\mathrm{BG}=$ Between Groups

$\mathrm{WG}=$ Within Groups

Data in Table 7 show that cal. F-value (20.69) was greater than the Tabled F-value (3.00). The hypothesis of no significant difference in the demographic pattern of SIBs of secondary school students according to age $(F=20.69>3.00$, $\mathrm{df}=2116, \mathrm{p}<.05)$ was, therefore, rejected.
Hypothesis 2

There is no significant difference $(\mathrm{p}<.05)$ in the mean demographic pattern of SIBs of secondary school students according to gender. Data testing this hypothesis are contained in Table 8.

Table 8. Summary of t-Test Analysis of no Significant Difference in the Demographic Pattern of SIBs of Students according to Gender $(n=2,119)$.

\begin{tabular}{lllllll}
\hline Variable & N & $\bar{X}$ & SD & t-cal. Value & df & t-Tab. value \\
\hline Gender & & & & & & \\
*SIB & & & & & & \\
Male & 1061 & 6.26 & 1.279 & 4.49 & 2117 & 1.96 \\
Female & 1058 & 5.99 & 1.410 & & & \\
\hline
\end{tabular}

* Significant at $\mathrm{p}<.05$

Results in Table 8 indicate that t-cal. value of test of hypothesis of no significant difference in the demographic pattern of SIBs among secondary school students according to gender $[\mathrm{t}(2115)=4.49>1.96, \mathrm{p}<.05)]$ was greater than the observed t-value. The hypothesis of no significant difference in the demographic pattern of unhealthy lifestyles of secondary school students according to gender was, therefore, rejected.

Hypothesis 3

There is no significant difference $(p<.05)$ in the mean demographic pattern of SIBs of secondary school students according to school type. Data testing this hypothesis are contained in Table 9. 
Table 9. One-way Analysis of Variance (ANOVA) of no Significant Difference in the Demographic Pattern of Unhealthy Lifestyles of Secondary School Students according to School Type $(n=2119)$

\begin{tabular}{llllllll}
\hline Variable & N & Sources of Variance & Sum of Squares & df & Mean Squares & Cal. F & Table F value \\
\hline *School type & \multirow{2}{*}{2119} & BG & WG & 75.277 & 2 & 37.639 & \multirow{2}{*}{20.968} \\
*SIB & & 3795.081 & 2116 & 1.794 & 3.00 \\
\hline
\end{tabular}

*BG $=$ Between Groups

*WG $=$ Within Groups

Table 9 shows that cal. F-value (20.97) was greater than the Tabled F-value (3.00). The hypothesis of no significant difference in the pattern of SIBs of secondary school students according to school type $(\mathrm{F}=20.97>3.00, \mathrm{df}=2116, \mathrm{p}$ $<.05)$ was, therefore, rejected.
Hypothesis 4

There is no significant difference $(p<.05)$ in the demographic pattern of SIBs of secondary school students based on education zone. Data testing this hypothesis are contained in Table 10.

Table 10. One-way ANOVA of no Significant Difference in the Demographic Pattern of SIBs of Students based on Education zone ( $n=2119)$.

\begin{tabular}{lllllll}
\hline Variable & N & Sources of Variance & Sum of Squares & df & Mean Squares & Cal. F \\
\hline Education zone & \multirow{2}{*}{2119} & BG & Table F value & 2 & 11.481 & \multirow{2}{*}{6.314} \\
*SIB & & WG & 3847.395 & 2116 & 1.818 & \\
\hline
\end{tabular}

*BG $=$ Between Groups

$*$ WG $=$ Within Groups

Data in Table 10 show that cal. F-value (6.31) was greater than the Tabled F-value (3.00). The hypothesis of no significant difference in the demographic pattern of SIBs of secondary school students based on education zone $(\mathrm{F}=$ $6.31>3.00, \mathrm{df}=2116, \mathrm{p}<.05)$ was, therefore, rejected.

\section{Hypothesis 5}

There is no significant difference $(p<.05)$ in the demographic pattern of SIBs of secondary school students according to class. Data testing this hypothesis are contained in Table 11.

Table 11. Summary of t-Test Analysis of no Significant Difference in the Demographic Pattern of SIBs among Secondary School Students according to Class ( $n$ $=2119$ ).

\begin{tabular}{|c|c|c|c|c|c|c|}
\hline Variable & $\mathbf{N}$ & $\bar{X}$ & SD & t-cal. & df & t-Table value \\
\hline Class & & & & & & \\
\hline $\begin{array}{l}* \text { SIB } \\
\text { JSS } \\
\text { SSS }\end{array}$ & $\begin{array}{l}1036 \\
1083\end{array}$ & $\begin{array}{l}6.01 \\
6.16\end{array}$ & $\begin{array}{l}1.370 \\
1.334\end{array}$ & -1.11 & 2117 & 1.96 \\
\hline
\end{tabular}

* Significant at $\mathrm{p}<.05$

Table 11 indicates that $t$-cal. value of test of hypothesis of no significant difference in the demographic pattern of SIBs of secondary school students according to class [ $\mathrm{t}(2117)=-$ $1.11<1.96, \mathrm{p}<.05)]$ was less than the observed $\mathrm{t}$-value. The hypothesis of no significant difference in the demographic pattern of SIBs of secondary school students according to class was, therefore, accepted.

\section{Discussion}

There is an unprecedented trend in cases of SIBs and other forms of injuries among adolescents globally $(1,27)$. With growing concern about rapid increase in SIBs Nigeria, SIBs are becoming public health issues $(13,14)$. Data on pattern of SIBs among students in Imo State will facilitate formulation of preventive strategies which are valuable tools that policy makers, school administrators, and state government can adopt. To the best of researchers' knowledge, this is first concerted effort aimed at ascertaining pattern of SIBs among secondary school students in Imo State.

Results of the study showed that students occasionally bullied their school mates while sustaining minor injuries $(\bar{X}=$ 2.07; $\mathrm{SD}=0.73)$. This is lower than cases of injuries reported in previous studies $(14,25,27)$. The lower case of SIBs could explained by restriction of the scope of this study to SIBs with focused on pattern of occurrence as against other studies that included other forms of injuries prevalent among adolescents either school-based or hospital settings. The finding is relatively in consonance with the findings of previous studies in Nigeria $(14,26)$. Although, results showed that students never attempted suicide and suicidal behaviours, suicidal ideation and suicide attempts have been reported among youths in Nigeria (26). For example, in South-West Nigeria about $20 \%$ of youths aged $10-17$ years reported suicidal thoughts and about $12 \%$ reported a suicide attempt-rather high (26). This implies that secondary school students in Imo State might have underreported other forms of SIBs or deliberately refused to give information on pattern of SIBs prevalent among them. Data generated through FGDG substantiated the quantitative by indicating that SIBs usually occurred among students but especially among male students who engaged in risk-taking or life-threatening activities.

Age is a significant predictor of many injuries but its effect varies between specific injury groups. Finding of this study shows that students of all age categories occasionally 
sustained minor injuries while bullying their school mates (10-13 years $\bar{X}=1.50 ; \mathrm{SD}=.63 ; 14-17$ years $\bar{X}=1.64$; SD $=.62$; above 17 years $\bar{X}=1.51 ; \mathrm{SD}=.61)$. Also, our finding shows that for pattern of SIBs among students based on age, there was significant difference $(\mathrm{F}=20.69>3.00 ; \mathrm{P}<0.05)$ within age groups. This observation is consistent with findings from other studies $(14,28)$.

Male students occasionally sustained minor injuries while bullying their school mates (Male $\bar{X}=1.73$; SD $=.64$ ). Considerable numbers of studies around the globe has reported similar findings $(28,29,30)$. This is probably because males have higher levels of sensation seeking and are more impulsive thus are more likely to engage in risky behaviour than females $(1,27)$. This finding conforms to other reports that injuries are more predominant among male adolescents than female adolescents. Also, our finding shows that for pattern of SIBs among students based on gender, there was significant difference $[\mathrm{t}(2,115)=4.49>1.96 ; \mathrm{P}<$ $0.05)$. This observation is consistent with findings from other studies $(14,28,30)$.This suggests that many actions leading to injuries including SIBs occur in moments of distraction or high emotion and the intent to injure may be peripheral to the action (14). Results derived from FGDG indicated that SIBs usually occurred among male students who engaged in risktaking or life-threatening activities.

Students in EBSS and MXSS occasionally sustained minor injuries while bullying their school mates (EBSS $\bar{X}=1.75$; $\mathrm{SD}=.64 ; \operatorname{MXSS} \bar{X}=1.60 ; \mathrm{SD}=.63$ ). The occurrence of most injuries in the school is in consonance with the findings of Jildehet al. $(14,28,31)$ among others. This underscores the importance of school environment in the causation of injuries. That majority of the injured persons initially sought help or was attended to by school mates or friends and eyewitnesses further implicate school as one of the major places of injury occurrence among in-school adolescents (14, $28,31)$.Also, our finding shows that for pattern of SIBs among students based on school type, there was significant difference $(\mathrm{F}=20.97>3.00 ; \mathrm{P}<0.05)$ among students. The finding is in relatively consonance with reports of previous studies $(28,31)$.

Students in all the education zones occasionally sustained minor injuries during bullying (OKEZ $\bar{X}=1.64$; SD $=.52$; OREZ $\bar{X}=1.60$; SD $=.65$; OWEZ $\bar{X}=1.53$; SD $=.68$ ). School location has been implicated in previous studies as one of the determinants of injuries including SIBs among youths $(26,28,29)$. Although, finding of the study showed that self-inflicted minor injuries via bullying were more predominant among students irrespective education other forms of SIBs besides suicide may have been underreported by students. Data generated through FGDG corroborated this assertion because students felt reluctant to give vivid information on specific forms of SIBs. Nevertheless, the finding conforms to finding of past studies $(26,28,29)$.

With respect to class, JSS and SSS students occasionally sustained minor injuries while bullying their colleagues (JSS $\bar{X}=1.62 ; \mathrm{SD}=.67$; SSS $\bar{X}=1.54 ; \mathrm{SD}=.58$ ). This finding was expected because class delineates people and sometimes is mark of identity with covert and non-covert attributes which may be acceptable or unacceptable, beneficial or risky. Class/grade of students may have profound effects on pattern of SIBs among students though there may variations in pattern of SIBs among junior and senior students. This result conforms to finding of previous study which showed that rates of $26 \%$ to $37 \%$ have been reported for US community-based samples of middle to upper class youths (9th to 12th graders) (27). This study was not devoid of shortcomings. First, data were collected through a self-reported structured questionnaire with FGDG. Though, a mixed method approach, responses to the occurrence and pattern of SIBs could not be verified. Given that it is not impossible that some of the study participants may have under-reported or misreported intentionally, especially for SIBs concomitant with school or familial problems. A precise evidence-based data should minimize this however such data are difficult to come by especially in developing nations including Nigeria. In addition, the possibility of recall bias cannot be rule out. Considering the probability that detail of cases of SIBs could be lost due to memory-decay, resulting in the inclusion of injury events that occurred outside the recall period. We recommended that a short recall period of 3-6 months should minimize this. Although, this study did take into cognizance risk and protective factors of SIBs, further studies are needed to understand the risk and protective factors of SIBs among this population. A thorough assessment of SIBs is, of the first step in understanding and therefore becoming able to intervene and treat these behaviours successfully. Favazza and Hollander recommended a simple inquiry about SIBs, which this study incorporated but the authors did not include initial psychiatric evaluation as part of the study. However, the questions contained in the questionnaire were deemed appropriate and valid enough to elicit responses that provided insights into the patterns of SIBs among secondary school students.

Given the aforementioned limitations, we suggest that generalizing the findings to other setting should be treated with caution. Despite these limitations, this is the first study to investigate pattern of SIBs among secondary school students in Imo State. It looked at a large population of students and is considered to be the baseline for future studies. Researchers' ability to concentrate entirely on students would be helpful for formulating SIBs prevention programmes for student population in similar settings.

\section{Conclusion}

This study has provided information on demographic pattern of SIBs among secondary school students in Imo State. The authors anticipated that this information will be relevant in raising the awareness level among policy makers and the public in general since the problem of SIBs receives little consideration in most of the developing world including Nigeria. 


\section{Recommendations}

Protective factors such as significant relationships that emphasize love, attention, care and fulfillment of psychological needs of affected students should be reinforced. Identification of risk factors of SIBs and implementation of efficacious approaches to SIBs elimination among students are indispensable. Parents and other important caregivers should be included in this process. In addition, a major setback to the design of effective SIBs prevention strategies in many developing countries including Nigeria is the attitude towards their relevance by the public, stakeholders in educational institutions and many policy makers. Imo State Ministries of Health and Information should lend logistic and manpower support to the State Universal Basic Education Board in the implementation of prevention strategies against SIBs in schools. Consequently, findings reported in this study need to be adopted and implemented on a broader scale.

\section{Authors' Contributions}

Dr. Benedicta Agu participated in the article writing, conception of the methodology, questionnaire administration, retrieval of filled copies the of questionnaire from students, and design of sampling procedures; Prof. Chuks Ezedum participated in the supervision, validation of instrument and edited the manuscript; Dr. Agbaje Samson participated in the article writing, formulation of questionnaire items, and conducted the statistical analysis.

\section{Acknowledgements}

The authors wish to acknowledge the cooperation of secondary school students who participated in the study. The authors also appreciate principals, classroom teachers, research assistants and students of participating schools who actively supported and voluntarily responded to the items in the structured questionnaire and FGDG.

\section{References}

[1] National Institute of Health (NIH) (2000). Health risk behaviour change in children and adolescents.Retrieved from http://:www.nih.gov/on 18th September, 2008.

[2] Fineran, S. (1996). Gender Issues of Peer Sexual harassment among teenagers. An unpublished Ph.D thesis Report, University of Illinois, Chicago.

[3] Visser, M.J., and Moleko, A. (2005). High risk behaviour of primary school learners.S Afr. J. Educ. 2005, 15(13), 130-138.

[4] Danga, D.I. \&Danga, H. (2004) Sexual harassment: A student's view from a Nigerian University. The African Symposium, (4), 1, Retrieved from http://www2.ncsn.edu/ncsu/acm/sexhass.htm on 13th July, 2006.

[5] Ezedum, C.E. (2004). Self-medication among typical Nigerian in-school rural adolescents.Nigerian Journal of Health Education.(NJHE), 12(1), 28-36.
[6] International Union for Health promotion and Education (1999). Lessons from Canada. In International union for health promotion and Education, the evidence of Health Promotion Effectiveness: Shaping Public health in a New Europe. (Part two. Pp. 134 - 144) Brussels: Luxembourg Press.

[7] Robyn, N. and Lam, L., (1999). Report: young males and Risk-taking http://www.thegeorgeinstitute.Org//library; 75024-3dpf.

[8] DeGuzman, M.R., \& Bosch, K.R. (2007). High risk behaviours among youths. Accessed May 11, 2008, http://:apps.nccd.cdc.govlyrbss

[9] Tate, B. G., \&Baroff, G. S. (1966b, March). The application of reinforcement theory to modification of self-mutilation behavior. Paper presented at the meeting of the Southeastern Psychological Association, New Orleans, LA.

[10] Simeon, D., \& Hollander, E. Ed. (2001). Self-injurious behaviors: assessment and treatment. American Psychiatric publishing, Inc.

[11] Favazza A, Rosenthal R. Varieties of pathological selfmutilation. BehavNeurol, 3, 77-85. 1990

[12] Favazza A, Simeon D. Self-mutilation in impulsivity and aggression. Edited by Hollander E. and Stein DJ. Chichester, England, John Wiley and Sons, 1995

[13] Udoh, D.O. and Adeyemo, A.A. (2013) Traumatic brain injuries in children: A hospital-based study in Nigeria. African Journal of Paediatrics and Surgery, 10, 154159.http://dx.doi.org/10.4103/0189-6725.115043

[14] Jephtha C. Nmor, Kehi H. Nwaka, Kensuke Goto, Junko Toyosawa, Daisuke Fujita (2013). High rate of injuries among students in Southern Nigeria: An urgent call to action. Health $5(12)$,

1965-1975. http://dx.doi.org/10.4236/health.2013.512266

[15] Fatmi, Z., Hadden, W.C., Razzak, J.A., Qureshi, H.I., Hyder, A.A. and Pappas, G. (2007) Incidence, patterns and severity of reported unintentional injuries in Pakistan for persons five years and older: Results of the National Health Survey of Pakistan 1990-94. BMC Public Health, 7, 152. http://dx.doi.org/10.1186/1471-2458-7-15 .

[16] Cowie, A.P. (eds) (1990). Oxford Advanced Learner's Dictionary of Current English. Oxford: Oxford University Press.

[17] Hornby, A.S. (2001). Oxford advanced learner's dictionary of current English ( $6^{\text {th }}$ ed.). New York: Oxford University Press.

[18] Pridemore, W.A., Andrew, I., \&Spivak, M.A. (2003). Patterns of Suicide Mortality in Russia.Suicide and Life-Threatening Behaviour, 23, 132-150.

[19] Houghton, M. (2006). American Heritage Dictionary of the English Language ( $4^{\text {th }}$ ed.). USA: Houghton Mifflin.

[20] Philips, D.P. (1991). Adequacy of official Suicide Statistics for Scientific Research and Public Policy, Suicide and Life Threatening Behaviour, 24, 304-310.

[21] Krohn, M.D., Massey, J.L., Skinner, W.E., and Laner, R.M. (1983). Social bonding theory and adolescent cigarette smoking: A longitudinal analysis. Journal of Health and Social Behaviour, 24, 337-349. 
[22] Igra, V., \& Irwin, C.E. (1996). Theories of adolescent risktaking behaviour. In R. Diclemente, W.B; Hansen, and L.E.; Ponton (eds). Handbook of Adolescent health Risk Behaviour New York, NY: Plenum Publishing Corp, 35 - 53.

[23] Hart, H.L.A., \& T., Honore, T. (1998) Causation in the Law. Retrieved fromhttp://:www.seavy,Supranotes On Sept, 1996.

[24] World Health Organization (2008) Violence, injuries, and disability: Biennial 2006-2007 report. World Health Organization, Geneva.

[25] Peltzer, K. (2008) Injury and social determinants among inschool adolescents in six African countries. Injury Prevention, 14, 381-388. http://dx.doi.org/10.1136/ip.2008.01859

[26] Omigbodun O, Dogra N, Esan O et al (2008). Prevalence and correlates of suicidal behaviour among adolescents in southwest Nigeria.The International Journal of Social Psychiatry, 54:34-46.

[27] Yates T, Tracy A, Luthar S (2008). Non-suicidal self-injury among "privileged" youths: longitudinal and cross-sectional approaches to developmental process. Journal of Consulting and Clinical Psychology, 76:52-62.
[28] Olawale, O.A. and Owoaje, E.T. (2007) Incidence and pattern of injuries among residents of a rural area in South-Western Nigeria: A community-based study. BMC Public Health, 7, 246.http://dx.doi.org/10.1186/1471-2458-7-246

[29] Pickett, W., Michal, M.K., Simpson, I.J., Emmanuel, K.J., Mazur, Y.H. and William, F.B. (2005) Cross national study of injury and social determinants in adolescents. Injury Prevention, 11, 213-218. http://dx.doi.org/10.1136/ip.2004.007021

[30] Moshiro, C., Ivar, H., Anne, N.A., Philip, S., Yusuf, H. and Gunnar, K. (2005) Injury morbidity in an urban and a rural area in Tanzania: An epidemiological survey. BMC Public Health, 5, 11.http://dx.doi.org/10.1186/1471-2458-5-11

[31] Jildeh, C., Abdeen, Z., Sabbah, H.A. and Philalithis, A. (2013) Unintentional injuries among school-aged children in Palestine: Findings from the national study of Palestinian schoolchildren (HBSC-WBG2006). International Journal of Population Research, 2013. 